20.1

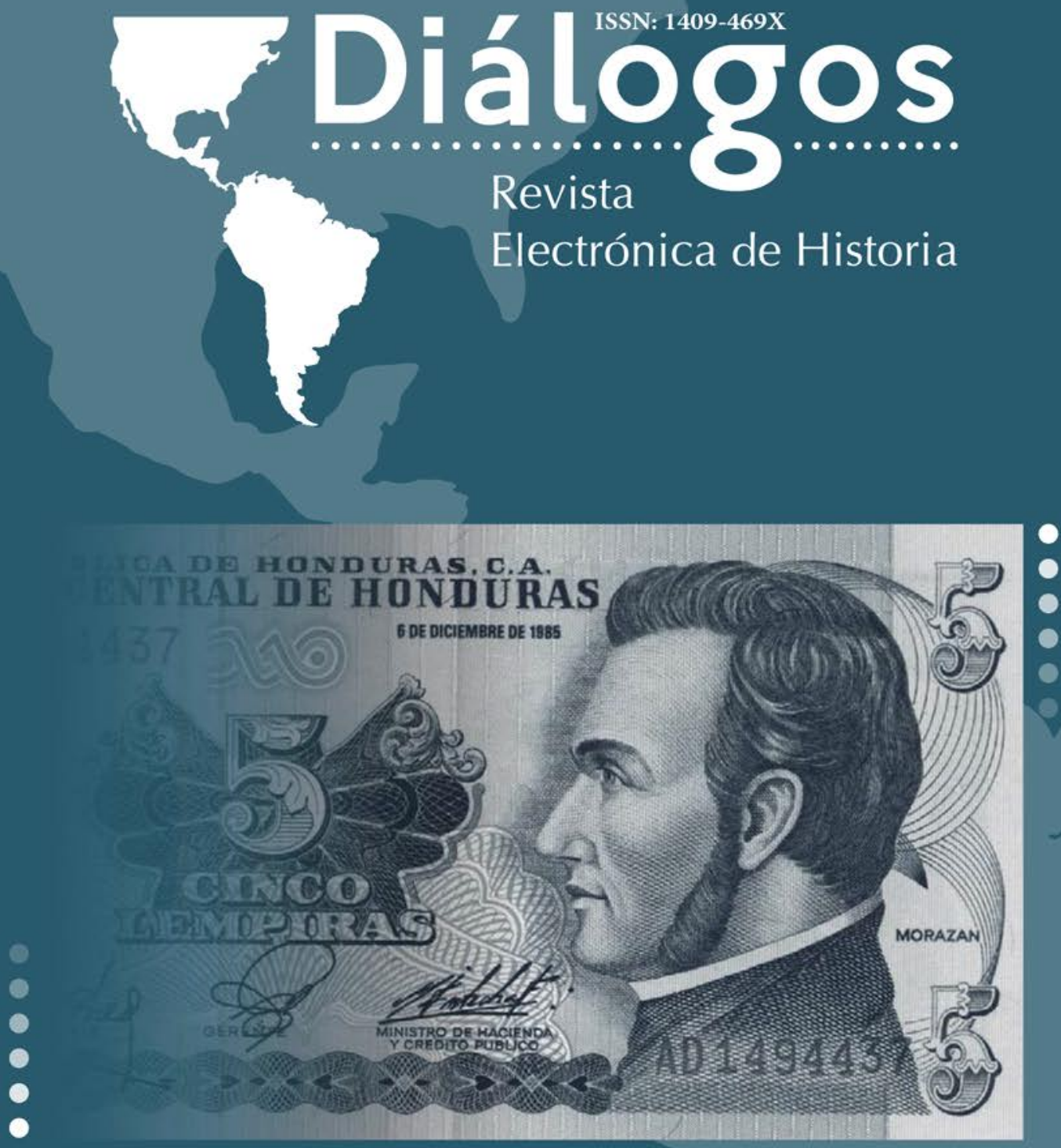

Centro de Investigaciones Históricas de América Central. Universidad de Costa Rica

\title{
Enero-junio 2019
}

url: http://revistas.ucr.ac.cr/index.php/dialogos/index

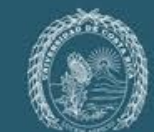

UNIVERSIDAD DE

COSTARICA

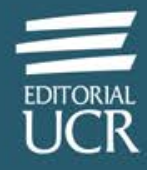




\title{
REVOLUCIÓN Y GUERRA CIVIL EN CENTROAMÉRICA: DOS CONCEPTOS EN EL PENSAMIENTO POLÍTICO DE FRANCISCO MORAZÁN
}

Vicente Gómez

\begin{abstract}
Resumen
La independencia y el proyecto de la república centroamericana en las primeras décadas del siglo XIX aparecen a menudo, junto con el resto de las revoluciones hispanoamericanas, designadas como procesos fallidos con respecto al modelo de revolución francesa y norteamericano. Este trabajo tiene como objetivo analizar los conceptos de revolución y guerra civil en el vocabulario político de Francisco Morazán, para con ello aportar a revisar esa visión de la historia latinoamericana. La vía metodológica elegida para aproximarse al pensamiento de la figura central del unionismo centroamericano es la historia de los conceptos de Reinkart Koselleck, junto con una debida contextualización histórica. Estas dos herramientas ayudaran a demostrar cómo, lejos de ser una desviación de un modelo, el proceso político centroamericano tuvo rasgos propios, cuyos actores históricos fueron conscientes y a partir de los cuales conceptualizaron su experiencia como parte de las transformaciones globales de la era de las revoluciones.
\end{abstract}

Palabras claves: historia, historia política, violencia.

\section{REVOLUTION AND CIVIL WAR IN CENTRAL AMERICA: TWO CONCEPTS IN THE POLITICAL THOUGHT OF FRANCISCO MORAZÁN}

\begin{abstract}
The Central American Independence and the project of a Central American Republic in the first decades of the 19th Century are often portrayed, along with the rest of the Spanish American Revolutions, as a deviation from an original model of revolution based on the French and North American experiences. The purpose of this paper is to analyze the concepts of revolution and civil war in the political thought of Francisco Morazán, champion of the Central American unity, to contribute to rethink the interpretation of Latin American history as a deviation. As for the methodological approach, the choice is for the conceptual history of Reinhart Koselleck and a proper historical contextualization. Together, these tools will help to show how the Central American political process had its own characteristics, which the historical actors were aware of and from which they thought their experience as part of the major global transformations of the Age of Revolutions.
\end{abstract}

Keywords: history, political history, violence.

Fecha de recepción: 14 de junio de 2018 • Fecha de aceptación: 23 de octubre de 2018

\footnotetext{
Vicente Gómez • Universidad de Costa Rica, Costa Rica. Docente en la Escuela de Historia y en la Escuela de Estudios Generales e Investigador del Centro de Investigaciones Históricas de América Central. Contacto: jvicente.gomez@gmail.com
} 


\section{INTRODUCCIÓN}

La particularidad de la independencia centroamericana, su carácter pacífico, que le ahorró una larga guerra entre facciones y contra el poder colonial, como las que ocurrieron en otras partes de América, es comúnmente contrastada en los relatos históricos con las guerras civiles que le siguieron en el período de la república centroamericana. Si bien es cierto que es importante hacer una distinción entre independencia y revolución, es indudable que en el continente americano la relación entre esos dos conceptos y procesos fue muy estrecha, particularmente en el caso de la Norteamérica Británica (Langley, 1996, p. 4). En Centroamérica, en cambio, revolución no es un concepto que se conecte automáticamente con el proceso de emancipación. Por supuesto, la ausencia de la violencia asociada comúnmente al concepto de revolución no es una razón menor para esa diferencia. La importancia del concepto de revolución en el período que va de 1750 a 1850 ha sido evidenciada por una extensa literatura que se ha ocupado de la llamada "era de las revoluciones" (Bayly, 2010, pp. 76-119). En su acepción moderna, es un concepto surgido de desarrollos extraordinarios de ese período, y en particular de uno: la Revolución Francesa (Koselleck, 2006, pp. 240-241). Revolución y guerra civil, como señala Armitage, son dos conceptos que guardan una estrecha relación en su historia. Mientras que revolución guarda un lugar positivo como una fuerza movida por la esperanza de una transformación para el bien, la guerra civil aparece como fenómeno impulsado por odios y malos sentimientos (Armitage, 2018).

A partir de lo anterior, se puede plantear lo siguiente: ¿De qué forma entendían los centroamericanos los conceptos de guerra civil y revolución en el período de la república centroamericana?:Qué usos hacían de estos conceptos y cómo los vinculaban con los procesos de transformación política de escala continental y atlántica que estaban en curso?

Estas preguntas hacen eco de la discusión en la historia intelectual que ha sido crítica con lo que Elías Palti llama el esquema de "modelos" y "desviaciones" (2018, p. 68), una crítica a la interpretación tradicional del paradigma proveniente de la historia de las ideas que ha observado en la historia de las ideas latinoamericana una mera reproducción mal lograda de los procesos revolucionarios francés y norteamericano. En la misma dirección, Jeremy Adelman ha señalado cómo las narrativas ancladas en el paradigma del Estado/nación han presentado a las revoluciones francesa y estadounidense como productos de fuerzas autónomas contenidas en fronteras rígidas, con el efecto de interpretar los procesos latinoamericanos como desarrollos movidos por los conceptos y luchas que se desbordaron de los límites de las revoluciones del norte y llegaron a América Latina, donde su recepción consistió en un esfuerzo de imitación (2018,p. 74).

Para empezar a ensayar respuestas a estas amplias preguntas, este trabajo las delimita al caso concreto de Francisco Morazán, la figura heroica del unionismo centroamericano (Lacaze, 2013); por lo tanto se plantea como objetivo analizar los conceptos de guerra civil y revolución en el vocabulario político de Francisco Morazán en el contexto de su acción política en la República Centroamérica. 
Para lanzarse a escudriñar la historia intelectual local centroamericana a través del caso del general hondureño, cuyos escritos han tenido una gran difusión en la región, la vía metodológica elegida es la Begriffsgeschichte, o historia conceptual, en la forma planteada por Reinhart Koselleck (1990a, pp. XIII-XXIV), una aproximación que es particularmente adecuada para comprender la manera en que Morazán entendía los procesos que vivía Centroamérica en las décadas posteriores a la independencia, porque permite seguir la pista, de manera sincrónica y diacrónica, a los usos y significados otorgados a conceptos fundamentales a los que recurrían los actores para dar cuenta de los procesos que experimentaban.

\section{LOS PROBLEMAS ABIERTOS POR LA INDEPENDENCIA.}

La ruptura del pacto colonial fue recibida con cautela y desconfianza por las élites de los territorios que hasta entonces habían conformado el Reino de Guatemala. Harto conocidas son las condiciones bajo las que se firmó el acta del 15 de setiembre en Guatemala, y que quedaron patentes en el primer artículo de dicha declaración, que rezaba: "Que siendo la independencia del gobierno español la voluntad general del pueblo de Guatemala (...) el Sr. Jefe Político la mande a publicar para prevenir las consecuencias que serían temibles en el caso de que la proclamase de hecho el mismo pueblo" (Meléndez, 1978, p. 61). El miedo a la revolución social, inspirado en otros episodios de violencia revolucionaria, particularmente el francés y más inmediatamente el haitiano (Knight, 2012, p. 346), tomaba en Centroamérica la forma de un temor a la desintegración del orden conocido que esta representaba. En adelante, los proyectos políticos de las élites centroamericanas estarían marcados por la misma preocupación por contener las fuerzas centrífugas que amenazaban con separar las partes del conjunto que había sido el Reino de Guatemala bajo el dominio español y, con ello, desbaratar el orden social imperante en este.

Tras largas deliberaciones sobre el modo más adecuado de hacer frente al quiebre con el poder metropolitano y habiendo ensayado un intento de una nueva monarquía bajo un emperador mexicano, las élites centroamericanas acordaron reunirse para intentar un proyecto nuevo: la construcción de una república autónoma sobre la base de la experiencia colonial. Esta apuesta constituyó el esfuerzo más importante por resolver el problema central que había abierto la independencia, y tomaría por lo menos hasta mediados del siglo XIX a los latinoamericanos vislumbrar un cierre para él; se trata del problema de construir una nueva legitimidad política para llenar el vacío dejado por el rey.

El nuevo estado que en julio de 1823 surgiera bajo el nombre de Provincias Unidas del Centro de América, abrió el horizonte de expectativas de los centroamericanos, que empezaron a contemplar en su nueva entidad política una vía para enfrentar las vicisitudes de un mundo dominado por grandes y poderosos imperios, donde en el sistema de las relaciones internacionales no existía espacio para que estados pequeños pudieran sobrevivir. Pronto se hizo claro que el rápido 
cambio político que introdujo la independencia no produjo cambios al mismo ritmo a nivel cultural. A pesar de que desde 1824 adoptara el nombre de república y se diera una constitución para organizar poderes federales y estatales, el proyecto que empezó con expresiones de unidad y optimismo por el futuro, dio paso a una gran inestabilidad en las instituciones que intentaba construir (Woodward, 1991, p. 7). En la década de 1830, el marqués Juan José de Aycinena criticaba a los constituyentes de 1824 por haber implantado un sistema político ajeno a las tradiciones de los pueblos centroamericanos y para el cual no estaban "listos" (Dym, 2006, pp. 199-202).

La primera elección para presidente de la república estuvo marcada por la desconfianza y las dudas en la legitimidad del elegido (Woodward, 1991, p. 12). Manuel José de Arce, electo por el parlamento y no en elecciones, se toparía con una oposición intransigente, y cualquier intento por reafirmar su autoridad y llevar adelante su programa de reforma moderado toparía con resistencia de parte de los liberales radicales y eventualmente también de los sectores conservadores con los que levantó una coalición para ascender a la presidencia (Woodward, 1991, pp.12-13).

Las disputas del gobierno federal con los gobiernos de los estados de Guatemala y El Salvador conducirían a la caída de Arce y al estallido de la primera guerra civil en la federación (1826-1829), que supondría la puesta en marcha de una política liberal radical de forma más decidida, solo para que esta encontrara su fin luego de casi diez años de incesantes brotes de guerra por tensiones entre el poder central y las partes, o por disputas de las provincias unas con otras o a lo interno de estas, motivadas por divisiones de clase o intereses económicos. De cualquier manera, hacia 1837, la figura de Rafael Carrera aparecería para cerrar este ciclo de ensayos liberales y relanzar la política conservadora, consolidándose a sí mismo como un nuevo factor en el cálculo político (Woodward, 1993). En este contexto, la lucha entre Rafael Carrera y Francisco Morazán, que seguiría hasta la extinción del proyecto federal, sería la forma más clara de las disputas que rasgaban la bandera de la unidad centroamericana en los años finales de la República Centroamericana (Woodward, 1991, 16-20).

Toda esta inestabilidad y violencia minaban la confianza en las posibilidades de éxito de la nueva república y mantenían abierto el problema de cómo construir una nueva soberanía en una fragmentada región, consumida por luchas entre partidos que hacían parecer que el intento por contener las fuerzas centrífugas desatadas por la independencia estaba fracasando. El largo espacio de experiencia colonial permitía a los centroamericanos imaginar un nuevo estado de cosas donde, unidos en una república, alcanzaran la promesa de la felicidad traída por la independencia; sin embargo, ese horizonte de expectativas se nublaba toda vez que la guerra civil carcomía las bases materiales y morales del proyecto. En sus campañas y administraciones, Francisco Morazán hizo frente a estos problemas, problemas que encontraban en las expresiones guerra civil y revolución, dos conceptos claves que reflejaban el estado de cosas en Centroamérica en las primeras décadas después de la independencia. 


\section{CENTROAMÉRICA. REVOLUCIÓN. GUERRA CIVIL.}

Las dos coyunturas de guerra civil más importantes en el período de la república centroamericana tuvieron lugar entre 1826-1829 y 1837-1840. El primer estallido de guerra culminó con el triunfo de Morazán y lo que difusamente se ha llamado liberalismo centroamericano, que significó el triunfo del federalismo frente al centralismo y el despliegue de un importante programa de impopulares reformas (sobre la economía, el sistema jurídico y la vida cultural) que contenían un considerable anticlericalismo, que a la postre sería utilizado por los sectores, de forma vaga también, denominados conservadores contra los liberales (Acuña, 2012, pp. 137-138). Si bien en 1826 estalla la guerra civil, ya desde antes en las viejas provincias distintas facciones locales se habían estado enfrentando; y en el período posterior a 1829, los niveles de violencia y represión utilizados por los vencedores para llevar adelante su programa de reformas provocaron un constante brote de rebeliones y malestar que conducirán a la rebelión de Rafael Carrera en 1837 y la derrota de Francisco Morazán en 1840 (Woodward, 1991, pp.15-20). Estos niveles de violencia hablan de la incapacidad del poder central federal de neutralizar las fuentes de violencia organizada en su territorio, un rasgo señalado por Robert Holden como indicador de la falta de legitimidad del poder público en Centroamérica y de su carácter improvisado (2004, p. 50).

En medio de la violencia de la lucha por el monopolio de la fuerza de que da testimonio la documentación que se analiza aquí, se encuentran varios usos de revolución y guerra civil que se podrían resumir en tres categorías: 1. revolución como evento, como alzamiento armado o cualquier desorden, 2. revolución como concepto que remite a un proceso histórico de transformación general a largo plazo y 3. la equiparación de revolución con guerra civil. En este último caso, aparece guerra civil como conflicto abierto entre miembros de una misma comunidad política, entre los miembros de la República Centroamericana; y revolución aparece como parte de ese conflicto o como su totalidad. Esta ambivalencia y polisemia son típicas de los conceptos fundamentales y, como se verá, podían ser intercambiables o podían aparecer como conceptos opuestos.

La historia conceptual de revolución y guerra civil es un ejemplo típico de dos conceptos que comparten un mismo campo semántico y que, por lo tanto, guardan importantes relaciones, en unas ocasiones de complementariedad y en otras de oposición. En la abundante entrada de "Revolution und Bürgekrieg" del Geschichtlile Grundbegriffe, Koselleck reconstruye con detenimiento el ascenso del moderno concepto occidental de revolución y su relación con el de guerra civil (Koselleck, 1990b, pp. 653-788). De acuerdo con él, sobre la base de las ideas romanas en torno a la guerra civil hay una serie de experiencias claves entre finales del siglo XVII y finales del XVIII que modifican los significados otorgados a revolución y guerra civil; la primera de ellas es la llamada "Revolución Gloriosa" de 1688 en Inglaterra; la segunda, la Revolución de independencia estadounidense; y la tercera, y culminante en el proceso de surgimiento del moderno concepto de revolución, la Revolución Francesa. 
Antecedentes a estas experiencias, como el uso de metáforas astronómicas desde el siglo XIV para describir el movimiento de la política, tuvieron el efecto de trasladar el concepto de revolución del campo de la astronomía al de la política (Koselleck, 1990b, pp. 718-721).

De las experiencias recién mencionadas surge un uso de revolución que lo pone en oposición a guerra civil. Para los ilustrados, la guerra civil representaba un vestigio del fanatismo de los partidos religiosos de las guerras de religión y de la guerra de los 30 años (Koselleck, 2015, 74-75). La superación de la guerra civil representaba, en este sentido, el progreso y la civilización frente a la barbarie. Al reflexionar sobre la experiencia de la "Revolución Gloriosa" de 1688 en Inglaterra, los ilustrados constataron que era posible la reforma del sistema político sin pasar por la violencia y el desorden de la guerra civil. Esto abrió la expectativa de una transformación que en la filosofía de la historia se expresó en la idea de una pacífica "revolución del espíritu," es decir, de la opinión pública y de la razón en el avance a la perfección de la sociedad (Koselleck, 1990b, 719-720). Sería a partir de 1789, con la Revolución Francesa, que finalmente revolución se convertiría en un concepto que indicaría un cambio estructural de largo plazo que abarcaría más allá de su asociación política inicial y cubriría otros espacios, sociales, culturales y económicos, y no un evento concreto como un alzamiento aislado con objetivos inmediatos. Por otra parte, que guerra civil permanecía atado aún a experiencias antiguas de desorden político, discordia, rebelión, tumulto, levantamiento; significados que están también asentados en las capas profundas de revolución (Koselleck, 2006, 241-24), y por eso estos pueden aparecer como sinónimos.

Esto último es frecuente en los escritos de Francisco Morazán: revolución y guerra civil no parecen guardar mayor diferencia la una de la otra, al menos en principio. Esto en sí ya es un indicador sugerente de la particularidad de la experiencia local. No hace falta un ejercicio de semántica cuantitativa para darse cuenta de la importancia de revolución en el pensamiento de Francisco Morazán. Es un concepto omnipresente en sus escritos y sin él hubiera sido imposible para el general hondureño dar cuenta del curso histórico de la república centroamericana; en él se recogían toda una serie de significados asociados a la experiencia de la inestabilidad política que siguió a la independencia.

\section{REVOLUCIÓN}

En julio de 1829, un victorioso Morazán expulsó a los principales líderes de la facción derrotada en la guerra que había iniciado en 1826. Entre estos se hallaba el marqués de Aycinena, Juan José Aycinena y Piñol, así como otros destacados miembros de las élites de la ciudad de Guatemala. Sobre este proceder Morazán comentó lo siguiente: "Mi obligación era hacer desaparecer hasta los más pequeños vestigios de la revolución, compensando de este modo la sangre vertida en tantos combates y los sacrificios hechos por los verdaderos centroamericanos" (Morazán, en Meléndez, 1996,p. 71). 
En vez de usar guerra civil, Morazán prefirió usar revolución para referirse a los últimos tres años de guerra que habían significado numerosos combates, muertos y recursos invertidos. Aquí se evidencia la apertura de estos dos conceptos, intercambiados sin mayor problema.

Esta relación sin oposición entre guerra civil y revolución, se aprecia nuevamente con claridad cuando a finales de ese mismo año de 1829, Morazán advertía en un comunicado que había restos de los derrotados que amenazaban con intentar recuperar el poder:

\footnotetext{
...el Ex-Presidente Arce...fue el primer autor de la guerra civil, y de las desgracias que se han experimentado en Centro América por más de dos años; ha querido ahora renovarlas, y promueve nuevas revoluciones, sembrando por todas partes la discordia; manteniendo la esperanza de los descontentos y valiéndose de los recursos que le prestan sus antiguas relaciones (Morazán, en Meléndez, 1996, p. 80).
}

Guerra civil aparece aquí como la suma de muchos brotes de violencia que son designados como revoluciones. El proceder de que acusaba Morazán a Arce y sus seguidores, descrito como una siembra de odios y como un avivamiento de los resentimientos, podía conducir a revoluciones, a motines y alzamientos contra el nuevo gobierno; y cuantas más revoluciones lograra encender Arce, más peligroso era que éstas desembocaran en una guerra civil. Este uso de revolución entonces, es opuesto a la idea ilustrada de revolución como un tránsito pacífico que superara la violencia de la guerra civil. Morazán era un conocedor de las ideas ilustradas, o por lo menos compartía una conciencia de modernidad que se estaba estableciendo en el mundo atlántico. Pero en la experiencia centroamericana, la independencia no había pasado por una revolución: no había una experiencia de cambio radical que sostuviera una noción de revolución que fuera en esa dirección. Por el contrario, el amotinamiento, el desorden y la violencia de la guerra civil eran la experiencia dominante, de manera que ese uso tradicional de revolución responde al contexto local.

Revolución estaba tan asociado a la experiencia de los brotes armados y las refriegas, que en 1831, advirtiendo de nuevo sobre la amenaza del expresidente Arce, Morazán escribió una proclama en la que hacía un uso de revolución como verbo al señalar que: "Arce y Domínguez que sólo pueden vivir en el desorden, han formado el proyecto quimérico de revolucionar a los pueblos y destruir el sistema federal" (Morazán, en Meléndez, 1996, p. 124). Perfectamente, revolución puede ser sustituido en la cita anterior por amotinar, o cualquier otro concepto que indique un alzamiento.

Entre los significados contenidos en los estratos profundos de revolución, provenientes de la historia griega y romana, se encuentra también conjuratio, o conspiración, que remitía a la idea de un grupo en permanente preparación en las sombras de un ataque contra el poder establecido. Ya en la cita recién introducida se puede notar un tono de denuncia de una conspiración fraguada por los derrotados. También en esa línea de una conjuratio podría haber habido alguna implicación en el uso de revolución para referirse a la expulsión de los líderes de los derrotados, como una forma de cortar la conspiración. 
Con más claridad se puede observar esto en la advertencia que lanzaba Morazán a los centroamericanos a finales de ese mismo año de 1829:

\begin{abstract}
PUEBLOS DE CENTROAMÉRICA: Mi carácter franco y vuestro interés, me hacen manifestaros la tormenta que se prepara contra vosotros, y los riesgos de que os véis rodeados. A vosotros toca descubrir a vuestros enemigos interiores, y a mi ofreceros nuevamente el sacrificio de mi vida y de mi reposo. Mantenéos unidos; alejad de vosotros las discordias, y el espíritu de partido; precabéos contra la seducción, y el engaño, y contra las maquinaciones de todos aquellos que intenten sembrar desconfianza contra los verdaderos patriotas. Ellos y estos ya son bastante conocidos, y la revolución los ha puesto al descubierto, para que no podáis equivocaros (Morazán, en Meléndez, 1996, p. 80).
\end{abstract}

La amenaza de nuevos alzamientos armados que mantenían en vilo a Morazán en la cita anterior, no significaba la revolución por la que Víctor Hughes, el personaje de Carpentier, conspiraba por las noches en reuniones masónicas o en cafetines (Carpentier, 1962/1985), era más bien la revancha de los derrotados con el objetivo específico de retomar el poder. La quimérica transformación de la sociedad en un nuevo paraíso de la igualdad y de la justicia, como soñaba Hughes para su isla en el Caribe, es parte del concepto de revolución posterior a 1789 que conecta con un horizonte de expectativas que alberga la visión de una transformación estructural de la sociedad. Y es este último significado el que, de forma llamativa, ocupa un lugar secundario en los escritos de Francisco Morazán.

De manera que el héroe centroamericano de la era de las revoluciones, no parecía un revolucionario según el modelo del orador que anunciaba el fin del viejo orden. $O$ por lo menos, su uso de revolución era restringido. De nuevo, esto se explica por el hecho de que Centroamérica no tuvo una revolución de independencia con sus episodios heroicos de masas con el pecho descubierto, asaltando palacios y enarbolando banderas que pudieran servir de experiencia para sostener un concepto de revolución que remitiera al tipo de proceso que desvelaba a Hughes y que respondía al modelo desplegado en Francia y la Norteamérica Británica. Sin embargo, ocasionalmente revolución aparece en los documentos morazánicos con una connotación que sugiere una concepción de proceso.

En 1842, desde Costa Rica, Morazán escribía una proclama anunciando la convocatoria, por medio de un decreto del 20 de julio de ese año, a una asamblea constituyente "llamada a la obra de regeneración de la República" (Morazán, en Meléndez, 1996, p. 330). Esa proclama era fundamentalmente una justificación de la acción unilateral de convocar a una asamblea constituyente y era un esfuerzo por convencer a los centroamericanos de atender al llamado; el "jefe supremo provisorio del Estado de Costa Rica," invocó la voz revolución en esa proclama:

La experiencia de nuestros propios yerros, la que de los hombres y de las cosas que hemos podido adquirir en una revolución de veinte años, y la ventajosa posición en que nos colocan los recursos con que contamos y la opinión pública que secunda nuestros esfuerzos, son suficientes motivos para que se persuadan estos honrados ciudadanos de la sinceridad con que hoy les extendemos nuestros brazos y brindamos nuestra amistad. (Morazán, en Meléndez, 1996, p. 332). 
Como se observa en las primeras líneas del texto, revolución es usado para designar el tiempo transcurrido desde la emancipación del Imperio Español hasta el presente en que fueron escritas esas líneas, en 1842. Esto es algo poco común; solo ocasionalmente en otras fuentes del período aparece un uso similar del concepto. Este uso algo ambivalente podría sugerir, por un lado, que los centroamericanos llevaban veinte años haciendo revolución, en un sentido de transformación general en todos los órdenes o, por el otro, que los últimos veinte años de cambio político eran entendidos como una revolución en sentido de desorden o guerra. En cualquier caso, hay un sentido acumulativo en el uso del concepto, y no precisamente un sentido acumulativo que signifique mejora o avance, como en el concepto de progreso, sino más bien es un sentido acumulativo de estancamiento, de no movimiento. La observación retrospectiva de Morazán alimentaba la advertencia que lanzaba al final del mensaje en caso de no atenderse su convocatoria a una denominada Asamblea Nacional Constituyente para salvar la república:

Pero si desgraciadamente fuesen desoídos nuestros votos, si no encontrásemos en el seno de la amistad, ni en el interés de una franca reconciliación, los medios de salvarla, el poder irresistible de la opinión pública sabrá trazar a nuestras armas el camino que nos conduzca a la victoria, y proporcionar a los centroamericanos un gobierno de leyes, que les dé paz, libertad y civilización (Morazán, en Meléndez, 1996, p. 332).

Si no había asamblea, Morazán haría la guerra, una guerra que se anunciaba para finalmente crear libertad y civilización, goces que no habían sido alcanzados, a pesar de la "revolución de veinte años"; es en este sentido que hay una noción de estancamiento implícita en el mensaje de Morazán: después de veinte años y muchas batallas luchadas, no aparecía la felicidad prometida por la independencia (Díaz y Viales, 2012). Aunque escrito con una pluma en una mano y un sable en la otra, el mensaje de Morazán no dejaba de ser una convocatoria que apelaba a la noción de soberanía popular para la formación de un nuevo gobierno: "El remedio de los males públicos exigía una medida grande y nacional, deducida del sistema representativo, que tuviese su origen en el pueblo y que fuese apoyada por la opinión" (Morazán, en Meléndez, 1996, p. 330). La retórica política y la práctica de guerra de Morazán verían su fin pronto, de manos de un levantamiento popular en Costa Rica que lo pondría en el paredón de fusilamiento.

Otro ejemplo donde se puede observar un sentido de proceso en el uso de revolución se encuentra en un mensaje que dirigió Morazán al congreso de los diputados centroamericanos al iniciar sus sesiones del año de 1831:

Las épocas legislativas que han precedido a la guerra civil, son fecundas en hechos, y abundan en suceso que debieran borrarse de la historia de nuestra gloriosa revolución. Pero ella los presentará a la posteridad con sus caracteres distintivos, y denunciará los nombres de los que aparentando en sus labios defender la libertad, han encendido hogueras en sus corazones para aniquilarla. El tiempo que os ha tocado a vosotros, ciudadanos representantes, es el más feliz que han disfrutado los pueblos desde su independencia: examinadlo (Morazán, en Meléndez, 1996, p. 112). 
En la cita aparecen en la misma oración guerra civil y revolución, y lo hacen en una dinámica que hace resonar con fuerza el talante de las nociones ilustradas en torno a estos dos conceptos. Revolución aparece aquí equiparable a independencia, la historia de la independencia es la historia de la revolución. Los diez años que han pasado desde 1821 son una "gloriosa revolución." Aquí revolución inclusive aparece como un concepto generador de expectativas: la historia se encargará de que en el futuro de la revolución, sus enemigos sean denunciados y puestos en evidencia. Es relevante señalar que este uso del concepto revolución, que lo asocia con el futuro, se da en un contexto de triunfo; desde hacía un año Morazán era presidente de la república y los conservadores habían sido derrotados y sus líderes expulsados del país, de manera que parecía un momento propicio para un cambio conceptual que reflejara el cambio histórico. Sin embargo, esto no fue duradero: incesantes amagos de revuelta hacían que nuevamente los significados asociados al conflicto armado volvieran a dominar al concepto.

Guerra civil, en cambio, aparece como una interrupción en el movimiento hacia el futuro que estaba desplegando la revolución, aun cuando se señale que son muchos los hechos que deberían borrarse en la historia de la revolución, esta aparece como una unidad en movimiento lineal. Guerra civil es estancamiento, un girar sobre sí misma que no permite avanzar; la "historia gloriosa" sugiere el movimiento lineal que se encuentra en el concepto ilustrado de progreso.

Por supuesto, esta acepción positiva de revolución tenía su cara oscura, que siguiendo el ejemplo de Saturno devoraba a sus hijos. En Centroamérica la revolución devoraba a sus hijos, y ese constante devorar se transformó en guerra civil, de forma que los significados positivos de proceso y cambio que se acaban de señalar, perdían fuerza frente a una realidad histórica dominada por la violencia de la guerra civil. Sin un relato originario de gesta heroica revolucionaria, la revolución en Centroamérica no se asemejaba a la Revolución Francesa o a la norteamericana y el resplandor que transmiten los relatos de esas revoluciones, en Centroamérica parece que apenas da para una tenue luz, opacada por el fantasma de la guerra civil. Sin embargo, lejos de esta visión de desvío de un modelo de revolución o de fracaso en imitar las revoluciones del norte, Morazán se mostraba consciente de las particularidades del proceso centroamericano y rebatía la ingenuidad que le achacaban sus enemigos, quienes afirmaban que los liberales intentaban llevar adelante la implantación de instituciones extranjeras incompatibles con los pueblos de la República Centroamericana:

\footnotetext{
En fin, atreverse a asegurar al público tantas falsedades juntas, es abusar demasiado de sus sencillez y buena fe, y del silencio que han observado los centroamericanos ilustrados, que conocen que ni los norteamericanos pudieron hacer su felicidad copiando las constituciones democráticas que habían servido a otros pueblos, ni el de Centro América, en su actual estado, hará la suya, adoptando la ley fundamental de aquella República, sino puede trasplantar al mismo tiempo el espíritu que le da vida (Morazán, en Meléndez, 1996, p. 294).
}

El problema, entonces, era construir instituciones que se alimentaran de las condiciones históricas centroamericanas. ¿Era la revolución una vía para lograr este objetivo? 
En el fondo, el problema que se atravesaba obstinadamente era el de la tradición versus el cambio, y en las múltiples aristas de ese problema estaban los enfrentamientos entre caudillos y facciones, localismos y regionalismos, cargados con resentimientos del período colonial, que se mostraban duros de quebrar. Héctor Pérez capturó muy bien la interpretación que podía hacer un personaje como Francisco Morazán de este difícil escenario: "Los liberales, enfrentados a la guerra civil y la reacción conservadora atribuyeron su fracaso a la persistencia del pasado colonial y a sus agentes presentes. La tarea revolucionaria quedaba todavía pendiente y era parte esencial de la agenda de reformas liberales en la segunda mitad del siglo XIX" (2017, p. 140).

Sin embargo, los desmanes de la guerra no habían conducido a Morazán, al menos en su retórica, a abandonar la idea del establecimiento de un gobierno representativo basado en el concepto de soberanía popular, noción que está en el centro de las enormes dificultades que experimentó Centroamérica para transitar a un nuevo régimen de tipo representativo, como los más "exaltados" lo imaginaban. La frustración de Morazán en la que sería su última acción por la república centroamericana lo hacía moverse entre amenazar con la guerra y pregonar la soberanía popular, cuya aplicación había producido resultados ambivalentes, o hasta contraproducentes, como señalaran los críticos "serviles". La importancia de los esfuerzos por materializar el principio de la soberanía popular es un rasgo común de los procesos de construcción de nuevas entidades políticas en todo el continente americano y une a Centroamérica con la historia de las revoluciones atlánticas y le da un lugar al conjunto de las revoluciones hispanoamericanas en la historia del surgimiento de la modernidad política, sitio que no habían tenido en las narrativas dominantes sobre este proceso (Sabato, 2018, pp. 1-2).

Los "veinte años de revolución" efectivamente introdujeron a nivel político cambios en dirección de la representación popular, o por lo menos hacia el desmantelamiento del régimen anterior: la emisión de constituciones, la abolición de los viejos privilegios aristocráticos, de los títulos nobiliarios y de la odiosa esclavitud fueron una realidad. Pero en el orden social y cultural, los cambios habían sido menos destacables; las masas centroamericanas desconfiaban de las nuevas instituciones que intentaba imponer el proyecto federal y las percibían como importaciones desde el extranjero. (Woodward, 1991, pp. 15-17). La cultura política centroamericana tenía pocas experiencias con elementos claves para el éxito de la soberanía popular como principio básico de legitimación del poder (como el ejercicio de la opinión pública o la alfabetización) y el peso cultural de la Iglesia Católica seguía siendo enorme, lo que condenó a la revolución a una cuestión de minorías (Pérez, 2017, p. 141).

Morazán demostraba un talante ilustrado en una afirmación como la de los "veinte años de revolución", sin embargo, la pregunta sigue abierta ¿se miraba a sí mismo como un líder que se colocaba a la vanguardia de esos veinte años para encausar y acelerar la historia hacía la transformación revolucionaria? A partir de sus escritos se desprende una imagen ambivalente, si bien revolución no aparece completamente como concepto de transformación general, sí hay una conciencia de modernidad que lo conecta con las ideas en ascenso en la época, como a otros de las minorías letradas centroamericanas. 
Por ejemplo, en 1842, Morazán justificaba su intervención en Costa Rica apelando a revolución en un sentido amplio de proceso continental: "Las excitaciones continuas de los costarricenses, oprimidos por un gobierno hasta hoy sin modelo en la historia de la revolución de la América española, que espero no tendrá imitadores, me obligaron a desembarcar en estas costas..." (Morazán, en Meléndez, 1996, p. 328).

Esta conciencia de modernidad se refleja en algunos documentos donde Morazán pone en evidencia que se miraba a sí mismo y a Centroamérica como parte de un proceso mayor, no solo de "la historia de la revolución de la América española," sino de un movimiento de revolución que cubría todo el Atlántico. En noviembre de 1830, comentaba con tono emocionado en una carta a un amigo personal sobre los alzamientos de artesanos y obreros parisinos que se expandieron hasta colocar a Francia en situación revolucionaria: "La Europa se ha conmovido con el suceso de París. Los soberanos del mundo antiguo se hallan en la dura alternativa de imitar a la Francia haciéndose constitucionales o de declararse la guerra. La situación de éstos y el espíritu del siglo creo que los obligarán a adoptar, a su pesar, lo primero" (Morazán, en Meléndez, 1996, p. 110).

Esta llamada "Revolución de 1830" se expandió al sur de Holanda a Italia, Polonia y algunos estados de la Confederación Germánica, y sus resultados fueron un debilitamiento general del orden reaccionario establecido en 1815, aunque este solo en Francia sufriría una derrota más completa, fue una revolución más política que social, aunque apeló a la retórica y estética de 1789 (Osterhammel, 2011, p. 768-769).

El carácter americano del proceso demostraba ser de gran importancia para Morazán; en la misma nota escribió, demostrando estar muy informado del acontecer en la antigua Nueva España y de las campañas de Simón Bolívar, que: "México sigue en partidos. El del Gobierno sufrió un gran revés últimamente, en el que murió el general Armijo. Colombia, la capital, está sitiada y vuelve Bolívar a triunfar de sus enemigos" (Morazán, en Meléndez, 1996, p. 110) y en diciembre de 1830, se regocijaba con un amigo personal de que: "Continúan muy buenas las noticias extranjeras. España, El Piamonte, y la Holanda, han seguido el ejemplo de París, aunque sus reyes no han venido abajo. En la Habana han causado gran impresión” (Morazán, en Meléndez, 1996, p. 111).

Pero será en el mensaje a los diputados en 1831 cuando Morazán ejerza con más claridad la noción de que Centroamérica es parte del contexto global de revolución que imperaba en las primeras décadas del siglo XIX. En esa oportunidad señaló a los diputados: "Hace pocos meses que el heroico pueblo francés reconquistó sus derechos usurpados por el poder y rompió los lazos que oprimían a varios pueblos de Europa. Desde entonces concibió esperanzas el Ejecutivo que esta gran Nación protegiese la independencia de los nuevos Estados Américanos, y lo manifestó el Congreso en 1830" (Morazán, en Meléndez, 1996, p. 116). Desear el reconocimiento de la independencia americana por Francia era expresión del valor simbólico de la Revolución Francesa en el imaginario de los contemporáneos, en palabras de Morazán Francia era: "...una gran Nación que ha conmovido a la Europa con sus triunfos y ha comunicado el sagrado fuego de la libertad a sus habitantes” (Morazán, en Meléndez, 1996, p. 116). 
Las citas recién colocadas, y a las que se apeló más arriba para demostrar la conciencia de Morazán de la particularidad del proceso político en Centroamérica, permiten volver sobre el problema de la idea de "revoluciones fallidas" o de "imitaciones" de un modelo de revolución proveniente del norte. Solo el contexto global de revolución permitía a Morazán mirarse como parte de un proceso que trascendía las fronteras de la República Centroamericana y le permitía identificarse con los éxitos o fracasos de la revolución en otras partes del mundo. La marginalidad de Centroamérica y su revolución sin revolución no significan que los centroamericanos no formaran parte de las transformaciones que experimentaba el mundo atlántico en este período; solo indican que cada sociedad tiene su propio ritmo de cambio y falsean las metanarrativas que presentan el tránsito a la modernidad como la historia de un ascenso constante, ignorando los reveses y los lados oscuros de la modernidad. La guerra civil, el desorden revolucionario, son la contraparte de ese relato feliz que se articuló en torno al concepto de progreso; la narrativa del progreso, como ha señalado la historiadora Birgit Aschmann, debe integrar "los elementos contrarios de lo destructivo, lo ambivalente, lo oscuro, lo decadente" (2013, p. 10), que no son desviaciones, sino partes en sí del proceso de modernización.

Morazán, lamentablemente, vivió la experiencia de todos esas ambivalencias y destrucciones que provocó el tránsito a la modernidad en Centroamérica. Sus esfuerzos por superar la fragmentación y encausar el proyecto republicano no dieron los frutos que prometían y el militar hondureño nunca dejó de atizar el fuego de la guerra civil en la república, y por ello su uso más frecuente de revolución se asocia a la violencia de la guerra civil.

Quizás un factor que explica que revolución no aparezca en su forma más acabada para el período en los escritos de Morazán, y que este apelara a significados más antiguos o solo parcialmente conectados con el concepto moderno ilustrado, sea el problema étnico; el temor a una guerra de castas, un factor que enfrentaron los latinoamericanos en general y que no existió en un proceso como la Revolución Francesa o la Norteamericana. Las nuevas repúblicas americanas, en cambio, habían heredado estructuras sociales dominadas por un imaginario racial que había echado profundas raíces a lo largo de tres siglos y que estaba muy interiorizado en los distintos grupos sociales (Halperin Donghi, 2013, pp. 46-48). En esa estructura, las mayorías indígenas y los grupos de sangre mezclada estaban subordinados y una verdadera revolución de la egalité destruiría ese orden de cosas, que privilegiaba a las élites mestizas que dirigían el proceso político, de manera que este componente étnico tiene que ver con el uso esquivo de revolución, y subraya el carácter conservador del proceso, como ya lo habían dejado claro desde el principio las élites guatemaltecas al firmar la independencia en 1821 "para prevenir las consecuencias que serían temibles en el caso de que la proclamase de hecho el mismo pueblo" (Acta de independencia de Centroamérica, en Meléndez, 1978, p. 61).

Cuando en 1838 Rafael Carrera lideraba a miles de campesinos indígenas armados, y un grupo de comisionados enviados para pactar una tregua con él 
regresaron sin resultados positivos, Morazán les envió una nota de agradecimiento por su labor en la que se podía leer lo siguiente:

\begin{abstract}
Mis constantes deseos porque el restablecimiento del orden se efectuase...sin derramar sangre y aun sin que se sufriera la menor desgracia, me obligaron a exigir de ustedes un servicio que ustedes y no más, han podido prestar...La guerra de la barbarie contra la civilización, los exigen de una manera que positivamente contrista. Sin embargo, a ustedes lo mismo que a mi, les acompañará la dulce satisfacción de haber hecho cuanto estaba a nuestro alcance, no sólo para salvar a estos pueblos, sino al mismo bandido y sus hordas, hasta el grado de humillarnos, entendiéndose con aquél y guardándole consideraciones que nunca mereciera" (Morazán, en Meléndez, 1996, p. 205).
\end{abstract}

Cuando, al mando de Carrera, miles de indígenas armados amenazaban a ciudad de Guatemala, entonces Morazán presentaba su lucha como una batalla entre la barbarie y la civilización. No es difícil observar que Morazán identifica aquí a las élites criollas con la civilización y a los indígenas con la barbarie. Esta forma del conflicto revela el viejo temor a una guerra de castas, que pesaba sobre las conciencias de las élites criollas toda vez que se detenían a reflexionar sobre la realidad multiétnica que habían heredado los estados de la república centroamericana. El historiador Montúfar y Coronado escribió que el desenlace de la guerra civil de 1823-1869 “....afirmó a los que resultado de la misma guerra pudieron fundar la oclocracia..." (citado en Taracena, 2002, p. 67). El gobierno de la plebe, la oclocracia, era la forma en que en 1837 este historiador guatemalteco recordaba la irrupción de las masas indígenas en el proceso político. Una observación que contenía una inquietud por la debilidad numérica de los criollos frente a la superior presencia indígena (Taracena, 2002, pp. 67-68).

Es llamativo, sin embargo, que aunque revolución no aparece expresamente en la documentación en su forma moderna, aparecen siempre usos que sugieren la circulación de algunos de sus rasgos. Por ejemplo, más arriba se citó un extracto de un documento en el que Morazán indicaba que "la revolución...ha puesto al descubierto," a los enemigos del pueblo centroamericano. Este uso de revolución presenta al concepto no solo como indicador, sino como factor dentro del proceso político. La revolución aparece convertida aquí en sujeto autónomo capaz de acción: hace, ejecuta, descubre y expele enemigos. Este rasgo, la transformación de la revolución en sujeto, surge después de la Revolución Francesa, cuando el concepto alcanza la condición de colectivo singular, es decir, cuando ha absorbido y cubierto todos los significados individuales de revolución, para convertirse en la revolución, en singular. Este uso indica la nueva experiencia de un proceso que no puede ser controlado, en el que el sujeto de la acción no son seres humanos, sino la revolución por sí misma (Koselleck, 1990b, pp. 734-737). Por ejemplo, el publicista alemán Konrad Engelbert Oelsner observaba en 1792: "Die Revolution hat Hand an den französichen Adel gelegt" (Oelsner, citado en Koselleck, 1990b, p. 735), "La revolución ha puesto su mano sobre la nobleza francesa." Según Morazán, de la misma forma, en Centroamérica la revolución había puesto la mano sobre sus enemigos, los había descubierto y expulsado del país. 


\section{GUERRA CIVIL}

Luego de tres años de guerra contra los conservadores, partidarios de una política más moderada y vinculados a las familias aristocráticas coloniales, en abril de 1829, Francisco Morazán, como jefe del llamado "Ejército defensor de la ley," emitía una proclama para todos los habitantes de Centroamérica. Desde la plaza de la recién conquistada Ciudad de Guatemala, el general hondureño anunciaba el fin de la guerra que desde 1826 se peleaba en la república. Al respecto de ese período que acababa, señalaba lo siguiente:

El deseado día de la paz ha llegado; el sagrado código de nuestras instituciones que ha conservado el patriota a costa de su sangre, lo presenta como un don precioso para los pueblos, y a su vista desaparece el tiempo de las desgracias. A este tiempo de ruinas y de horrores, de devastaciones y de crímenes, se sucederá el del orden, y en él tendrán su trono la justicia y la ley, que osaron destruir los tiranos de Centro América (Morazán, citado en Meléndez, 1996, p. 53).

Con esto, el victorioso Morazán demostraba una concepción de guerra civil cercana al concepto ilustrado de la bellum intestinum. La guerra intestina aparece retratada aquí como un período de calamidades y desorden, y refleja una dimensión temporal. Esa dimensión temporal frustraba a muchos centroamericanos del período; era la sensación de estancamiento. La guerra civil, en vez de avanzar, representaba un movimiento sobre sí misma que solo dejaba destrucción y horrores. Por eso, Morazán, que intentaba en su proclama introducir una dimensión temporal distinta, quería subrayar el día de la paz como un quiebre y salida del movimiento circular de la guerra civil en favor de un tiempo nuevo. En marzo de 1830, en una carta a Lucas Alamán, entonces secretario de relaciones exteriores mexicano, advertía Morazán que Centroamérica se encontraba aún resentida "por la guerra civil que acaba de sufrir y la que hizo retroceder en su marcha política..." (Morazán, citado en Meléndez, 1996, p. 99). Revolución no aparece en esta oportunidad como el concepto de movimiento que rompa el vicioso círculo de la guerra civil, aunque como se vio más arriba, en otras ocasiones sí hubo un uso de revolución que sugería este sentido, particularmente al hablar de una "gloriosa revolución" que avanzaba desde la independencia y que había sido interrumpida por la guerra civil.

El sentido de estancamiento incorporado en el concepto de guerra civil quedó plasmado en el discurso de toma de posesión de Morazán en 1830, cuando señaló que "los funestos vicios del sistema colonial se transmiten entre nosotros, de padres a hijos, y el trastorno y las revoluciones que se han repetido en los Estados desde su independencia, son la escuela en donde aprende a conocer sus derechos esa desgraciada y preciosa porción de la República [la juventud] que es la destinada a consolidar el sistema que nos rige" (Morazán, en Meléndez, pp. 107-108). La guerra civil no permitía a los centroamericanos salir del mundo colonial: en un movimiento circular se perpetuaba de padres a hijos y oscurecía las posibilidades de educación y esclarecimiento para los que debían llevar adelante la transformación de Centroamérica: los jóvenes. La apelación a la educación como herramienta para la construcción de la república es parte del espíritu ilustrado de Morazán, por eso se lamentaba de que esta: 
"Lejos de adquirir virtudes republicanas ha tenido ejemplos funestos en esos monstruos de desorden, que nacen y mueren con las revoluciones" (Morazán, en Meléndez, 1996, p. 117).

Para quebrar el movimiento circular con que la guerra civil atrapaba a los centroamericanos, Morazán instaba a los diputados del congreso en 1836 a que llevaran adelante su labor legislativa:

\begin{abstract}
"Elegidos por la libre voluntad del pueblo para...romper y pulverizar, en fin, esa funesta cadena de revoluciones y de desastres, forjada por la mano de la venganza, por el mezquino interés privado, por el monstruo implacable que preside a los partidos, y principalmente por las pasiones innobles de los que no ven en el orden actual de cosas sino la ruina y exterminio de sus antiguos privilegios; es a vosotros a quienes pertenece emprender con energía y firmeza esta obra digna de vuestras luces y patriotismo, y dar al pueblo en la mejora de sus instituciones, dicha, reposo y gloria" (Morazán, en Meléndez, 1996, p. 183).
\end{abstract}

Aquí aparece la guerra civil como una "funesta cadena de revoluciones y desastres," de manera que revolución no parece un concepto contrario a guerra civil o como la salida de su círculo vicioso. Este es el Morazán constitucionalista, espera ver la realización de la revolución por vías institucionales y no por las armas. Por supuesto en 1836, Morazán no había sido expulsado de Guatemala por su enemigo, Rafael Carrera.

Este último, en los escritos de Morazán, es la encarnación de la guerra civil y de todos sus males. En 1841, en el conocido Manifiesto de David, que era una reivindicación de los liberales y una condena a los conservadores, el depuesto general dejó palabras llenas de repudio por el caudillo guatemalteco:

\footnotetext{
Y para que nada faltase de ignominoso y de funesto a la revolución que habéis últimamente promovido, apareció en la escena el salvaje Carrera, llevando en su pecho las insignias del fanatismo, en sus labios la destrucción de los principios liberales, y en sus manos el puñal que asesinara a todos aquellos que no habían sido abortados como él, de las cavernas del Mataquescuintla. Este monstruo debió desaparecer con el cólera morbus asiático que lo produjo. Al lado de un fraile y de un clérigo se presentó por primera vez revolucionando los pueblos contra el gobierno de Guatemala, como envenenador de los ríos que aquellos conjuraban, para evitar, decían, el contagio de la peste. (Morazán, citado en Meléndez, 1996, p. 295).
}

Aparte del evidente desprecio por su enemigo, Morazán utilizaba aquí revolución para designar la revuelta contra el gobierno liberal que catapultó a Rafael Carrera como un caudillo militar en Guatemala. Sin embargo, pronto Carrera funcionó como un catalizador de los derrotados en 1829, y el conflicto desbordó en guerra civil enfrentando a los mismos bandos de diez años atrás para terminar entre 1838 y 1840 con la unidad real de la república y dejar a las partes libres de los vínculos federales (Woodward, 1991, pp. 18-20). A diferencia de la transformación semántica ilustrada europea, que vio el ascenso de revolución como un concepto opuesto a la guerra civil, en Centroamérica revolución no se entendía como un concepto liberador de la guerra civil, sino más bien como un componente de esta. 
Como se mencionó más arriba, Morazán descargó toda su furia sobre Carrera en el Manifiesto de David y lo convirtió en la encarnación de todos los males de la guerra civil: "Su vida forma una cadena no interrumpida de delito, acompañada de circunstancias horrendas." Violaciones, asesinatos, saqueos, ejecuciones sumarias, decapitaciones, quema de pueblos enteros, todos estos crímenes se los atribuía Morazán a Carrera (Morazán, en Meléndez, 1996, pp. 294-298). Era como si en un solo hombre se pudieran encontrar todos los excesos de la violencia de las guerras de religión; los horrores que tanto impactaron a los ilustrados que buscaron encontrar en el concepto de revolución la superación de esos males.

Usar revolución para referirse a la guerra civil también podía tener la intención de deslegitimar a los rivales. Los liberales en el poder verían la guerra civil como un levantamiento ilegal de rebeldes contra el gobierno que, por supuesto, consideraban legítimo. Reconocer el estado de guerra civil sería otorgar un grado de legitimidad al enemigo, así que calificarlo como rebelde era una estrategia para desprestigiarlo, estrategia que Morazán siguió a menudo contra Carrera. De esto, hay importantes ejemplos, como cuando entre 1880 y 1901 se publicaron en los Estados Unidos setenta volúmenes de una historia oficial de la guerra civil de 1861-1865, titulada La guerra de la rebelión, con la clara intención de denostar al bando perdedor (Armitage, 2018).

Estudios recientes sobre la guerra federal de 1823-1826 han prestado una minuciosa atención al conflicto, desde el punto de vista de la historia social, económica y de la construcción de los estados nacionales en Centroamérica. Los ensayos editados por Arturo Taracena en el libro La primera guerra federal centroamericana, son particularmente esclarecedores de los costos materiales y humanos de la guerra (2015, pp. IX-XXV) y las fuentes del período no han fallado en transmitir una imagen de lo brutal de esas guerras que hicieron palidecer el sueño de la felicidad tras la independencia. Las descripciones de los crímenes de la guerra que hace Morazán abundan en detalles, y no menos detalladas son las descripciones de las tropas desarrapadas que deambulaban arrastradas por sus oficiales por los distintos estados de la República. Por ejemplo, en abril de 1829 Morazán escribía al gobierno federal que aliviara la situación de la tropa: "Cada día es mayor la desnudez de una gran parte del ejército, llegando al extremo de no salir a formar algunas compañías por hallarse enteramente desnudos" (Morazán, en Meléndez, 1996, p. 46).

Después de la siguiente cita de Carl Schmitt: "A la guerra civil es inherente cierta atrocidad. Es una guerra entre hermanos porque se libra en el marco de una unidad política común [...] y porque ambos bandos beligerantes afirman y al mismo tiempo niegan su unidad común con igual rotundidad" (citado en Armitage, 2018), David Armitage señala que: "Este es el motivo por el que las guerras civiles nos horrorizan; no debemos subestimar el papel de las guerras civiles en su exigencia de reconocimiento de pertenencia común en medio de la confrontación, es decir, en la formación de una mirada que nos obliga a reconocernos en el espejo del enemigo" (Armitage, 2018). Quizás Morazán se reconocía a sí mismo en el espejo de Carrera; 
tras doce años de sofocar alzamientos, perseguir guerrilleros, asediar ciudades, ejecutar prisioneros, pelear batallas y guerras civiles, Morazán y Centroamérica habían conocido más el horror de la guerra que la virtud de la paz.

La República Centroamericana estaba exhausta. En el clima de guerra civil había sido imposible construir una economía integrada en la república; como informara el vicepresidente de la república al congreso en 1835, en Centroamérica estaban: "Cegados todos los manantiales de las rentas, interrumpida la agricultura y destruido el comercio, anulado el crédito interior y exterior, depredadas las haciendas y labores; inseguros o alejados los propietarios principales..." (Gaceta del Gobierno Federal, citado en Pinto, 1993, p. 115). La guerra que entre centroamericanos se peleó durante el período de la república federal no careció de esa "inherente atrocidad" que señala Schmitt. En el siglo XX, la guerra civil alcanzará nuevas dimensiones y el concepto de revolución jugará un papel clave en ese contexto, que, por supuesto, se sale de los alcances de este trabajo. Sin embargo, es pertinente señalar la necesidad de un estudio de la guerra civil en Centroamérica en la larga duración.

\section{CONCLUSIÓN}

En este trabajo se ha seguido la pista a los usos y significados otorgados por Francisco Morazán a los conceptos de revolución y guerra civil. La polisemia y ambivalencia son los principales rasgos de estos dos conceptos en el pensamiento del militar hondureño. Un rasgo propio de los conceptos sociopolíticos fundamentales, que más que definidos pueden ser discutidos.

El caso de Morazán revela cómo, a través de estas dos categorías, los centroamericanos que vivieron en las primeras décadas del siglo XIX enfrentaron los problemas abiertos por la independencia. El tránsito del mundo colonial hacia nuevas entidades políticas basadas en el principio de soberanía popular fue designado en unas ocasiones como revolución y en otras como guerra civil. Estos conceptos aparecen intercambiables puesto que la experiencia de la guerra en la república centroamericana impedía que la noción moderna de revolución, como concepto de transformación social, se desplegara, y más bien se imponían los significados contenidos en este asociados a la violencia de la guerra y los amotinamientos. Sin embargo, Morazán era un individuo impregnado del espíritu del siglo, es decir, un simpatizante de las ideas ilustradas y compartía la conciencia de modernidad que se extendía en el contexto global de la era de las revoluciones.

Las implicaciones de esto en términos de su pensamiento, eran la convivencia de significados antiguos con nociones ilustradas en los conceptos de revolución y guerra civil. El caso de revolución es particularmente claro en este sentido. Aunque es el uso menos frecuente, revolución aparece en momentos importantes como concepto para dar cuenta de los cambios en curso a nivel continental y del mundo atlántico y a través de este, Morazán imaginaba a Centroamérica como parte de estos procesos. La función de revolución como concepto fundador de expectativas, apareció al hacer Morazán 
uso de revolución en sentido de proceso, por eso la esperanza de la consecución de la felicidad, como promesa de la independencia, aparecía asociada a revolución algunas veces. Pero el uso dominante de revolución tendía a ser el de designar los incesantes estallidos armados en la república, que amenazaban con reiniciar la guerra civil.

Lejos de ser la desviación o deformación de un modelo de revolución, el proceso político centroamericano de la independencia y el proyecto federal, revelan tener rasgos y problemas propios, de los cuales sus actores eran conscientes y luchaban por resolver. La revolución y la guerra civil no son desvíos del relato de progreso de la modernidad, son la otra cara de la moneda del proceso de modernización y deben ser integrados al relato de este. Morazán y sus contemporáneos intentaron acelerar los cambios que vivían, con lo cual experimentaron una gran frustración al chocar una y otra vez con el peso poderoso de la tradición. Y esto revela a su vez los límites de la independencia como proceso liberador, en tanto que dejó por fuera a grandes porciones de los centroamericanos, especialmente a los indígenas, que cuando se alzaron en armas, aparecieron retratados como la barbarie. La tarea de la revolución quedaba aun por llevarse acabo cuando hacia 1840 la república centroamericana desaparece, para quedar solo como una añoranza; una en la que están contenidas también las expectativas de construir un bloque centroamericano que de manera más efectiva pudiera hacer frente a los imperativos de un mundo que en el siglo XIX empezaba a ser dominado por la lógica de mercados mundiales. Esta lógica ha alcanzado nuevas alturas y hoy, bajo el nombre de Sistema de la Integración, sigue vigente la noción de que sus retos pueden ser atendidos desde la unidad centroamericana.

Es importante preguntarse por la historia de revolución y guerra civil en la larga duración, porque son dos conceptos que, sin ninguna experiencia en el mundo colonial que les dieran un sustrato fuerte, pasaron a ocupar un lugar central en el siglo XIX después de la independencia; y en el siglo XX alcanzarían dimensiones aún mayores y hasta globales. En la década de 1980 estuvieron en el centro de los desgarres sociales y políticos y hoy nuevamente amenazan como un fantasma las tierras centroamericanas. Hay que preguntarse qué papel jugará el concepto de revolución en los acontecimientos en curso en Nicaragua, ¿será revolución nuevamente el concepto para el proceso de cambio social? o acudirán los jóvenes nicaragüenses a otros conceptos para articular su lucha, justamente contra un régimen que construye su legitimidad sobre los acontecimientos revolucionarios de 1979? ¿Qué pasará con el mito de la revolución sandinista? ¿Habrá un proceso de construcción de nuevos significados?. Esta es la ventaja de los conceptos políticos fundamentales: pueden rehacerse y acumular en sus estratos nuevos significados que les permitan dar cuenta de un nuevo estado de cosas. Revolución, desechado después de 1990 como un concepto guía de la acción política, permanece aún hoy vigente como un concepto fundador de expectativas.

Los ilustrados del siglo XVIII estaban profundamente influenciados por la noción kantiana de una ewigen Frieden, una paz perpetua que superara los horrores de la guerra (Kant, 1998 [1795]). Los pueblos centroamericanos ansían y reclaman esa paz, y no quieren que sea la paz de la tumba, como en el anuncio de la posada holandesa de Kant. 
Como historiadores debemos aportar a la construcción de esa paz, y podemos empezar por señalar que aún de las peores experiencias, las sociedades han acumulado valiosas lecciones; como señala David Armitage, los retos que plantean las guerras civiles y las revoluciones han influenciado nuestras ideas sobre algunos elementos fundamentales de la convivencia moderna:

\footnotetext{
"Sin los desafíos que ella planteó [la guerra civil], nuestras ideas de democracia, política, autoridad, revolución, derecho internacional, cosmopolitismo, humanitarismo y globalización, para mencionar solo algunas, habrían sido muy diferentes, incluso más pobres. La experiencia de la guerra civil - los esfuerzos para entenderla, mejorarla e incluso evitarla - también ha modelado, y sigue conformando hoy mismo, nuestras ideas de comunidad, autoridad y soberanía. Las guerras civiles tienen origen en profundas y mortíferas divisiones, pero también exponen identidades y rasgos "comunes. Llamar «civil» a una guerra es reconocer la familiaridad de los enemigos en tanto miembros de una misma comunidad, esto es, no extranjeros, sino conciudadanos" (Armitage, 2018).
}

Hay muchas metáforas políticas sobre la revolución y la guerra civil, pero quizás una que lleva una marca local y que refleja la experiencia centroamericana al combinar la experiencia de vivir en una tierra montañosa y sísmica, con la de la vivencia de la destrucción de la guerra, sea la que se puede observar en las pancartas de los estudiantes nicaragüenses que luchan contra Daniel Ortega: "Juntos y unidos somos un volcán”, que recuerda la advertencia de Francisco Morazán refiriéndose al peligro de nuevos alzamientos armados contra la república al finalizar la primera guerra civil en 1829: "Nos hallamos sobre un volcán cuya superficie pintoresca nos hace olvidar la reunión de materias combustibles que se acumulan en sus entrañas próximas a agitarse y a ser envueltos en su explosión” (Morazán, en Meléndez, 1996, p. 110).

\section{REFERENCIAS}

Acuña, V. H. (2012). El liberalismo en Centroamérica en tiempos de la independencia (1810-1850). En J. Fernández Sebastián (Ed), La aurora de la libertad. Los primeros liberalismos en el mundo iberoamericano. Madrid: Marcial Pons.

Adelamn, J. (2018). Empires, Nations and Revolutions. Journal of the History of Ideas, 79(1), 73-88.

Adelman, J. (2008). An Age of Imperial Revolutions. The American Historical Review, 113(2), pp. 319-340.

Armitage, D. (2018). Las guerras civiles. Una historia en ideas. Madrid: Alianza Editorial. ISBN ebook: 978-84-9181-051-3

Aschmann, B. (2013). Der Traum der Vernunft und seine Monster. Goyas Persperktiven auf das 19. Jahrhundert. Berlín: Duncker \& Humblot.

Bayly, C.A. (2010). El nacimiento del mundo moderno, 1780-1914. Madrid: Siglo XXI Editores. 
Carpentier. A. (1962/1985). El siglo de las luces. Barcelona: Bruguera.

Díaz, D. y Viales, R. (2012) Futuros deseados y temidos: representaciones sobre el porvenir político en la Centroamérica independentista, 1821-1824. Boletín AFEHC, (53). http://afehc-historia centroamericana.org/index.php?action=fi_aff\&id=3088/rbcontent

Dym, J. (2006). From Sovereing Villages to National States. City, State and Federation in Central America, 1759-1839. Albuquerque: University of New Mexico Press.

Halperin, D. Tulio (2013). Historia contemporánea de América Latina. Madrid: Alianza Editorial.

Holden, R. H. (2004). Armies Without Nations : Public Violence and State Formation in Central America, 1821-1960. Cary: Oxford University Press.

Kant I. (1998). Sobre la paz perpetua. Madrid: Editorial Tecnos.

Knight, F. W. (2012). Haití en las revoluciones americanas. En P. Cagiao Vila y J. M. Portillo Valdés (Eds.), Entre imperio y naciones: Iberoamérica en torno a 1810 (pp. 341-363). Santiago de Compostela: Universidad de Santiago de Compostela, Servicio de Publicaciones e Intercambio Científico.

Koselleck, R. (1990a). Geschichtliche Grundbegriffe. Historisches Lexikon zur politisch-sozialen Sprache in Deutschland. Stuttgart: Klett-Cotta. Tomo I.

Koselleck, R. (1990b). Geschichtliche Grundbegriffe. Historisches Lexikon zur politisch-sozialen Sprache in Deutschland. Stuttgart: Klett-Cotta. Tomo V.

Koselleck, R. (2006). Begriffsgeschichten. Frankfurt: Suhrkamp Verlag.

Koselleck, R. (2015). Vergangene Zukunft. Franfkfurt: Suhrkamp Verlag.

Lacaze, C. (2013). Acercamiento al proceso de heroización de Francisco Morazán en América Central (1848, 1892, 1942). Revista Estudios, (26), pp. 1-16. https://doi.org/10.15517/re.v0i26.8844

Langley, D. L. (1996). The Americas in the Age of Revolution, 1750-1850. New Haven: Yale University Press.

Meléndez, C. (1978). Documentos fundamentales del siglo XIX. San José: ECR.

Meléndez, C. (1996). Escritos del general Francisco Morazán. Tegucigalpa: Banco Central de Honduras.

Osterhammel, Jürgen. (2011). Die Verwandlung der Welt. Eine Geschichte des 19. Jahrhunderts. München: C. H. Beck.

Palti, E. (2018). Revising History: Introduction to the Symposium on the Bicentennial of the Latin American Revolutions of Independence. Journal of the History of Ideas, 79(1), 65-71.

Pérez, H. (2017). El laberinto centroamericano: los hilos de la historia. San José: Centro de Investigaciones de América Central. 
Pinto, J. (1993). La independencia y la federación (1810-1840). En H. Pérez (ed.), Historia General de Centroamérica. Tomo III. Madrid: Ediciones Siruela.

Sabato, H. (2018). Republics of the New World. The Revolutionary Political Experiment in Nineteenth-Century Latin America. New Jersey: Princeton University Press.

Taracena, A. (2002). Etnicidad, estado y nación en Guatemala, 1808-1944. Guatemala: Nawal Wuj.

Taracena, A. (2015). La primera guerra federal centroamericana, 1826-1829. Naciones y estados, republicanismo y violencia. Guatemala: Editorial Cara Parens.

Woodward, R. (1993). Rafael Carrera and the Emergence of the Republic of Guatemala, 1821-1871. Georgia: University of Georgia Press

Woodward, R. L. (1991). The aftermath of Independence, 1821-c.1870. En L. Bethell (ed.), Central America since Independence (1-36). Cambridge: Cambridge University Press. 